\title{
LIST OF APPENDICES
}

Appendix DR1. Methods

p. 1

Appendix DR2. Archival Data

p. 3

Ti and bulk grain size data (Figure DR1)

p. 3

Radiocarbon results (Table DR1)

p. 3

Grain size versus settling velocity (Figure DR2)

p. 4

Vertical grain-size distribution for the 1350 yr BP deposit (Figure DR3)

p. 5

Variations in thickness of the 1350 yr BP deposit (Figure DR4)

p. 6

Appendix DR3. Wave runup estimates for the 1928 AD hurricane

p. 7

Appendix DR4. Estimated flow, shear velocities and head losses

p. 8

Appendix DR5: Significance of sediment resuspension

p. 10

Appendix DR6. Discussion of deposit genesis: hurricanes versus tsunamis

p. 14

References

p. 15

\section{Appendix DR1. Methods}

Cores were collected using a Vohnout/Colinvaux piston corer in 5-cm diameter polycarbonate barrels. Short $10-\mathrm{cm}$ diameter push cores were taken at select core locations in order to better capture the sediment/water interface and provide adequate material for radio-isotopic analyses. These push cores were extruded in the field and sampled every $0.5 \mathrm{~cm}$. Measurements of the activity of Cs-137 (a product of atmospheric nuclear weapons testing) were conducted using a high-resolution gamma detector. The locations for all coring sites were determined using a handheld GPS unit, which provided a horizontal accuracy of 3 to 6 meters. Sediment cores were split in the laboratory and select core halves were run through a non-destructive automated core scanner to obtain millimeter to sub-millimeter resolution X-ray fluorescence measurements of the sediment's elemental composition based on methods described by Croudace et al. (2006). Initial grain size analysis was conducted on contiguous $1 \mathrm{~cm}$ bulk samples using a Beckman-Coulter LS13320 laser diffraction particle size analyzer. After the coarse grained events were identified with the LS13320, isolated coarse grain layers were sub-sampled at $1 \mathrm{~cm}$ resolution. Clay and silt were removed from these 
isolated deposits using a $63 \mu \mathrm{m}$ sieve and the sand was dried and run through a digital image processing particle size and shape analyzer (Retsch Camsizer system) to obtain accurate grain-size distributions for the coarse fraction of each sample. After initial grain-size analyses for the bulk sediment, each overwash sample was treated with $\mathrm{H}_{2} \mathrm{O}_{2}$ and $\mathrm{HCl}$ solutions to remove organics and carbonate material and the remaining sediment was dried and re-run through the Camsizer system again to obtain grain-size distributions for the now isolated siliciclastic material. Each sample was run through the Camsizer system a minimum of three times to ensure reproducibility and the average of these runs was used for analysis. In order to quantify the settling rate for siliciclastic and shell material from the site, both of these materials were independently sieved using 10 consecutive bin sizes between $63 \mu \mathrm{m}$ and $2000 \mu \mathrm{m}$. This binned sediment was then settled through a $1.5 \mathrm{~m}$ long, hanging pan settling tube using methods described by Syvitski et al (1991).Samples of wood, seeds, and shells were radiocarbon dated at the NOSAMS Facility at Woods Hole Oceanographic Institution (WHOI). Resulting radiocarbon ages were calibrated to calendar years using the IntCal04 (Reimer et al., 2004) and Marine04 (Hughen et al., 2004) calibration data sets. Ages are reported in calendar years before present (BP) with present being 1950 A.D. by convention. References to historic events are reported in years A.D. 


\section{Appendix DR2. Archival data}

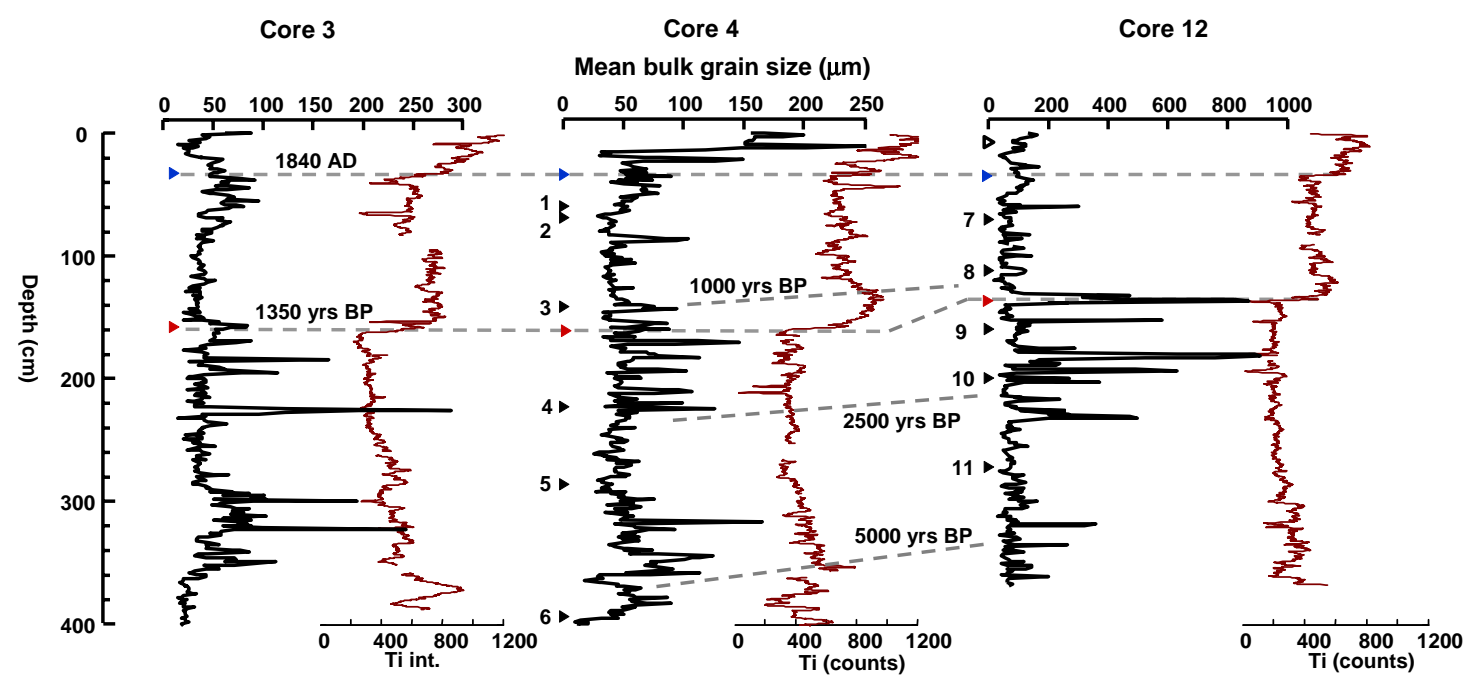

Figure DR1: Ti and bulk grain size data. Mean bulk grain size (black) and Ti measurements (red) for cores collected along the middle shore-normal transect at LPG (see Figure 1 in main text for core positions). Solid black arrows represent the depth of radiocarbon dated samples from Core 4 and Core 12 with sample index numbers referenced in Table DR1. The depth of abrupt increases in Ti which dates to $\sim 1840 \mathrm{AD}$ and $\sim 1350 \mathrm{yr}$ BP are noted with solid blue and red arrows, respectively (ages based on a linear interpolation between Cs-137 and C-14 dates obtained from Core 12, but are also consistent with C-14 dates obtained from Core 4). Dashed grey lines indicate depths of equal age base on the presented chronological constraints. Figure adapted from Donnelly and Woodruff (2007).

TABLE DR1. LAGUNA PLAYA GRANDE RADIOCARBON RESULTS*

\begin{tabular}{lclrrrrl}
\hline \hline $\begin{array}{l}\text { Index } \\
\text { Number }\end{array}$ & Core & Depth $(\mathrm{cm})$ & $14 \mathrm{C}$ date & Cal yrs BP & $(2 \sigma)$ & \multicolumn{1}{l}{ d13C } & \\
\hline 1 & 4 & $61-62$ & $125+45$ & 104 yrs BP & $(-2-277)$ & -25.59 & woody debris \\
2 & 4 & $70-71$ & $340+20$ & 369 yrs BP & $(314-467)$ & -26.71 & woody debris \\
3 & 4 & $143-144$ & $1140+25$ & 1010 yrs BP & $(969-1168)$ & -18.91 & seeds/woody debris \\
4 & 4 & $224-225$ & $2810+30$ & 2503 yrs BP & $(2438-2690)$ & -2.03 & Gastropods shells (Heleobops sp.) \\
5 & 4 & $286-287$ & $3320+30$ & 3500 yrs BP & $(3472-3633)$ & -17.22 & Seeds/woody debris \\
6 & 4 & $394.5-395.5$ & $4840+35$ & 5597 yrs BP & $(5479-5651)$ & -23.65 & wood \\
7 & 12 & $70-71$ & $240+30$ & 295 yrs BP & $(0-428)$ & -28.23 & wood \\
8 & 12 & $112-113$ & $940+30$ & 846 yrs BP & $(791-925)$ & -28.46 & wood \\
9 & 12 & $161-162$ & $1970+45$ & 1914 yrs BP & $(1821-2037)$ & -25.92 & wood \\
10 & 12 & $201-202$ & $2570+40$ & 2728 yrs BP & $(2495-2762)$ & -26.07 & wood \\
11 & 12 & $273-274$ & $3750+45$ & 4116 yrs BP & $(3978-4242)$ & -25.03 & wood \\
\hline
\end{tabular}

${ }^{*} \mathrm{C}-14$ data originally presented in Donnelly and Woodruff (2007) 


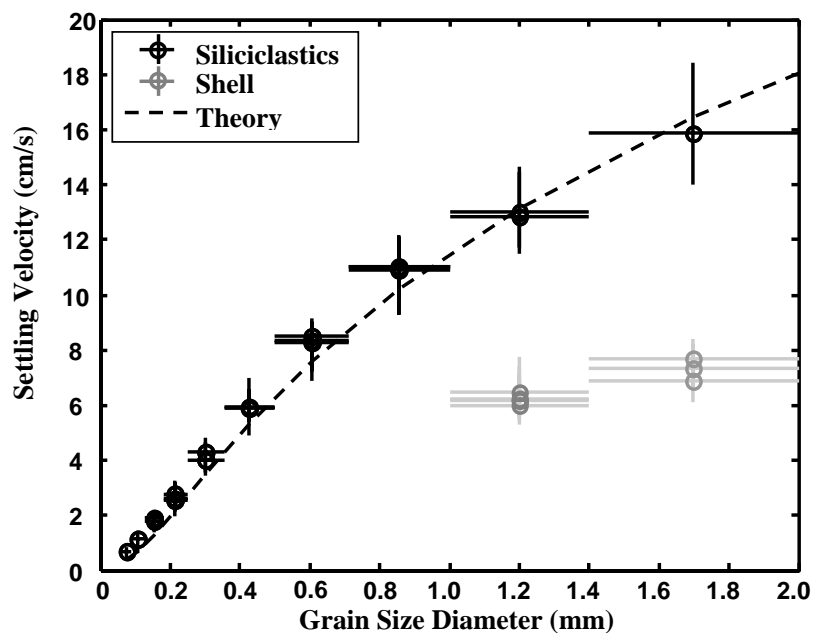

Figure DR2: Grain size versus settling velocity for LPG sediment. Mean settling velocities $\left(w_{s}\right)$ measured for siliciclastics (black circles) and shell material (gray circles). Vertical error bars indicate $1 \sigma$ range for $w_{s}$ and horizontal error bars indicate ranges of grain diameters in each bin size. Comparisons between the actual mean settling velocities measured for LPG siliciclastics sediments and values predicted by Ferguson and Church (2004) for naturally shaped quartz sands (black dotted line) reveal an excellent fit and support using the relationship for analyses in this study. 

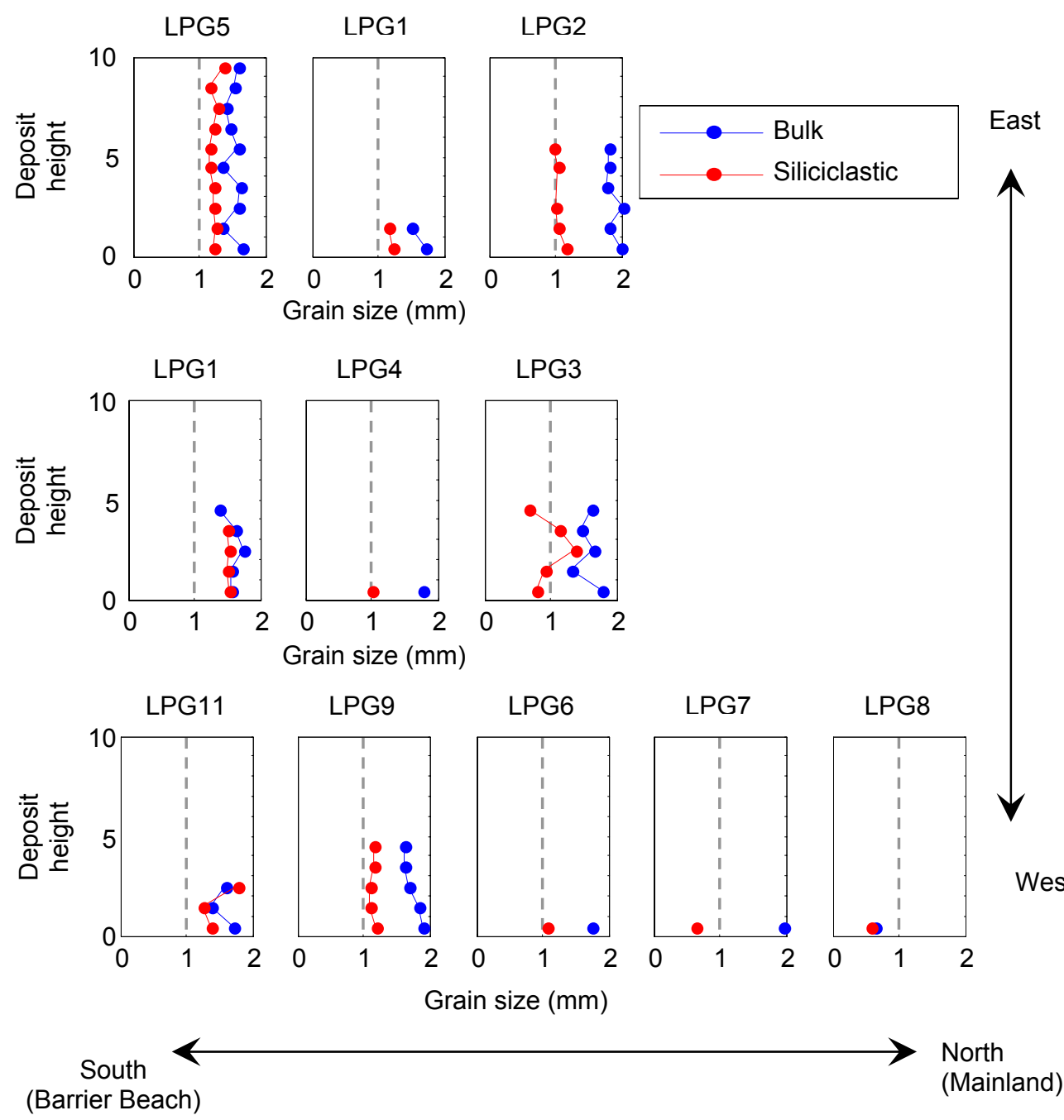

Figure DR3: Vertical grain-size distribution for 1350 yr BP deposit. Vertical variations in grain size (for material $>63 \mu \mathrm{m}$ ) measured at $1 \mathrm{~cm}$ increments from the $1350 \mathrm{yr}$ BP deposit. Bulk measurements are plotted in blue and measurements for siliciclastics are in red. Cores are arranged along the three shore normal transects with arrows indicating orientation (See site map in Fig. 1 of main text for core locations). 


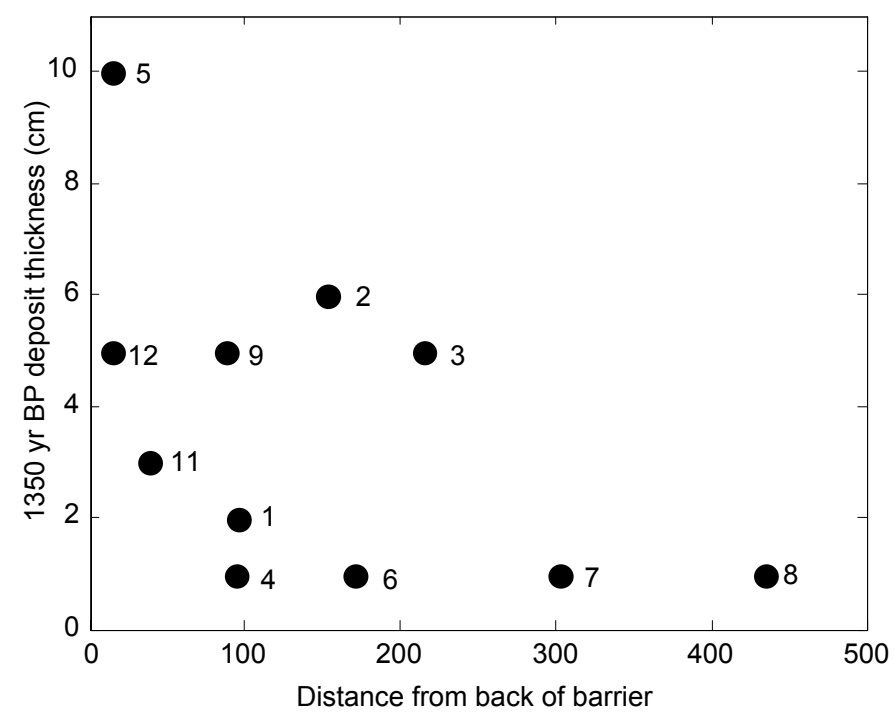

Figure DR4: Shore-normal variations in deposit thickness for 1350 yr BP deposit. Numbers represent coring locations identified in Fig. 1 of main text. The thickness of the deposit was variable but generally thinned away from the barrier and towards the mainland. 


\section{Appendix DR3: Wave runup estimates for the 1928 AD event at LPG}

Wave heights at the LPG barrier during a hurricane are significantly smaller than offshore due to breaking in the surf zone. This cross-shore gradient in wave height is balanced by an increase in water level onshore whose time-averaged mean is defined as wave setup (Fredsoe and Deigaard, 1992). The vertical oscillation in water elevation about this time-averaged mean is defined as swash. Wave runup is the cumulative constructive effect of wave setup and swash (Stockdon et al., 2006). The wave setup $\left(\eta_{\text {setup }}\right)$ and $2 \%$ exceedance value for runup $\left(R_{\max }\right)$ have been empirically related to the offshore significant wave height $\left(H_{o}\right)$, wavelength $\left(L_{o}\right)$ and the slope of the beach $(\beta)$, (Stockdon et al., 2006). In addition, for an extremely dissipative beach where $\beta$ is small relative to the offshore wave steepness $\left(\beta /\left(H_{o} / L_{o}\right)^{1 / 2}<0.3\right)$, Stockdon et al. (2006) suggests that a more accurate approximation can be obtained using, $R_{\max }=\alpha\left(H_{o} L_{o}\right)^{1 / 2}$, where $\alpha$ is 0.016 and 0.043 for $\eta_{\text {setup }}$ and $R_{\max }$, respectively.

The 1928 AD hurricane passed just $75 \mathrm{~km}$ to the south of LPG with an average maximum sustained wind speed $\left(U_{\text {wind }}\right)$ of $72 \mathrm{~m} / \mathrm{s}$ and a central pressure $\left(P_{\mathrm{o}}\right)$ of $931 \mathrm{mbar}$ (Landsea et al., 2004). Estimates of $H_{o}$ for the 1928 AD event range between $17 \mathrm{~m}$ and 16 m, using the separate empirical relationships $H_{o}=0.235 U_{\text {wind }}$ and $H_{o}=0.2\left(P_{r}-P_{o}\right)$, described respectively by Ochi (1998) and Hsu et al. (2000). Here $P_{r}$ is the pressure at the edge of the storm ( 1013 mbar). These wave heights are similar to those recently measured during Hurricane Ivan in 2004 (Wang et al., 2005), where a dominant wave period of 17 seconds and a corresponding wave length of $450 \mathrm{~m}$ was observed. For the $1928 \mathrm{AD}$ event we therefore assume a value of $16.5 \mathrm{~m}$ and $450 \mathrm{~m}$ for $H_{o}$ and $L_{o}$, 
respectively. Wind speeds are slightly slower during Ivan $\left(U_{\max }=60 \mathrm{~m} / \mathrm{s}\right)$ than estimated for the $1928 \mathrm{AD}$ event suggesting that the estimates for $1928 \mathrm{AD}$ wave dimensions might be considered a lower bound for the actual conditions occurring during the event.

The beach slope at LPG is approximately 0.05 which suggests highly dissipative conditions during the $1928 \mathrm{AD}$ event $\left(\beta /\left(H_{o} / L_{o}\right)^{1 / 2}=0.26\right)$. Based on the approximations presented by Stockdon et al. (2006) we estimate values for $\eta_{\text {setup }}$ and $R_{\max }$ of $1.4 \mathrm{~m}$ and $3.7 \mathrm{~m}$, respectively during the $1928 \mathrm{AD}$ hurricane.

\section{Appendix DR4: Estimating flow, shear velocities and head losses}

A rough approximation for how wave heights might diminish while propagating across the lagoon at LPG is obtained by using Bernoulli's principle to estimate the total energy head in the fluid and then accounting for the head lost by the fluid due to frictional interactions with the bed. The total head, $H$ for waves entering the lagoon can be approximated by:

$$
H=\frac{U_{b}^{2}}{2 g}+h_{b}
$$

Where $\mathrm{g}$ is gravity, $U_{b}$ is the mean flow velocity and $h_{b}$ is the average flow depth in the bore while propagating over the barrier (see Fig. 1B in the main text for schematic). Estimated values for $h_{b}$ range between 2 and $4 \mathrm{~m}$ based on the reconstruction for Core 3 presented in Figure 4 of the main text. Assuming flow is critical over the barrier crest, these wave heights correspond to flow velocities of $4.4 \mathrm{~m} / \mathrm{s}$ and $6.3 \mathrm{~m} / \mathrm{s}$, and values for $H$ ranging from $3 \mathrm{~m}$ to $6 \mathrm{~m}$. 
The total head lost by waves traveling a distance $L$ in the lagoon due to

friction is estimated as:

$$
\Delta H=\frac{u_{*}^{2} L}{g h_{L}}
$$

Where $u *$ is the shear velocity in the lagoon which can be related to the mean flow, $U_{L}$, with a non-dimensional drag coefficient, $C_{D}$ :

$$
u_{*_{L}}=\sqrt{C_{D}} U_{L}
$$

Here we assume a logarithmic velocity profile to obtain $C_{D}$ :

$$
C_{D}=\left(\frac{\kappa}{\ln \left(h_{L} / z_{o}\right)-1}\right)^{2}
$$

Where, $\kappa$ is von Karman's constant $(0.40), z_{o}$ is approximately equivalent to $d_{50} / 12$ and $d_{50}$ is the median grain size of the bed material, $\sim 100 \mu \mathrm{m}$ (Fig. DR1, Soulsby, 1997). We assume that the lagoon has already been partially flooded when the largest storm waves enter $\left(h_{o} \approx 2 \mathrm{~m}\right)$, such that mean flow velocities within the bore when propagating across the lagoon can be expressed as: $U_{L}=\frac{h_{L}-h_{o}}{h_{L}} \sqrt{g h_{L}}$ (Whitham, 1974). Rough approximations for $U_{L}$ and $h_{L}$ can be obtained numerically for given values of $U_{b}$ and $h_{b}$ assuming flow is conserved $\left(U_{b} h_{b}=U_{L} h_{L}\right)$. Based on these approximations we estimate values of $u *$ range between $8 \mathrm{~cm} / \mathrm{s}$ and $15 \mathrm{~cm} / \mathrm{s}$ (Table DR2). Using the distance of Core 3 from the back of the barrier as $L(214 \mathrm{~m})$ and estimated values for $u_{*}$ yield a head loss of approximately $0.04 \mathrm{~m}$ to $0.09 \mathrm{~m}$ for $2 \mathrm{~m}$ to $4 \mathrm{~m}$ high bores propagating across the lagoon to core site 3 . The head loss due to friction therefore represents only a small fraction 
$(\sim 1 \%)$ of the total energy head of waves entering the lagoon, and suggests that frictional effects should not significantly diminish the considered wave heights at the LPG site.

TABLE DR2. FLOW VELOCITY, SHEAR VELOCITY AND HEAD LOSS ESTIMATES

\begin{tabular}{lcccccccc}
\hline \hline $\begin{array}{l}h_{b} \\
(\mathrm{~m})\end{array}$ & $\begin{array}{c}U_{b} \\
(\mathrm{~m} / \mathrm{s})\end{array}$ & $\begin{array}{c}H \\
(\mathrm{~m})\end{array}$ & $\begin{array}{c}h_{o} \\
(\mathrm{~m})\end{array}$ & $\begin{array}{c}h_{L} \\
(\mathrm{~m})\end{array}$ & $\begin{array}{c}U_{L} \\
(\mathrm{~m} / \mathrm{s})\end{array}$ & $C_{D}$ & $\begin{array}{c}u_{*_{L}} \\
(\mathrm{~m} / \mathrm{s})\end{array}$ & $\begin{array}{c}\Delta H \\
(\mathrm{~m})\end{array}$ \\
\hline 2 & 4.4 & 3 & 2 & 3.5 & 2.5 & 0.001 & 0.08 & 0.04 \\
4 & 6.3 & 6 & 2 & 5.4 & 4.6 & 0.001 & 0.15 & 0.09 \\
\hline
\end{tabular}

\section{Appendix DR5: Significance of sediment resuspension}

The advective/settling model assumes that flows initially traveling over the barrier suspend coarse grained sediment high into the water column due to intense vertical mixing by breaking waves and enhanced turbulence in the boundary-layer. Once this flow enters the lagoon, turbulence is reduced significantly. The high concentrations of coarse grained sediment suspended by flows over the barrier can therefore no longer be sustained in the lagoon and sediment settles out at a rate far greater than what is resuspended from the bed. To test this assumption we compare estimates for the flux of suspended sediment from the barrier to those that could be produced just by resuspension in the lagoon. The equilibrium volumetric suspended sediment transport rate, $q_{s}$ is obtained both along the barrier and within the lagoon by taking the integral through the water depth for the product of the estimated flow velocities, $U(z)$ and suspended sediment concentrations, $C(z)$ during inundation,

$$
q_{s}=\int_{z_{a}}^{h} U(z) C(z) d z
$$


Where $z_{a}$ is a reference height above the bed at which a reference concentration $C_{a}$ is calculated, and $h$ is the water depth (Graf, 1971). For a sediment concentration profile we assume a linear increase in eddy diffusivity with height so that,

$$
C(z)=C_{a}\left(\frac{z}{z_{a}}\right)^{-R o}
$$

In this expression, $R_{o}$ is the Rouse number or suspension parameter, $R_{o}=w_{s} / \kappa u_{*}, w_{s}$ is the particle settling velocity, $\kappa$ is von Karman's constant $=0.4$, and $u *$ is the total shear velocity. Note that Equation 5.2 does not assume that sediment concentrations go to zero at the water surface and is therefore more suited for our application when compared to a typical Rouse profile with a parabolic eddy diffusivity profile (Soulsby, 1997).

To obtain $C_{a}$ we use the expression described by Smith and McLean (1977), McLean (1992), and Wiberg et al. (1994):

$$
C_{a}=f_{i} C_{b e d} \frac{\gamma_{o} S}{1+\gamma_{o} S}
$$

In this expression $f_{i}$ is the fraction of sediment in class $i, C_{b e d}$ is the maximum permissible volume concentration in the bed (1-porosity), $\gamma_{o}$ is the resuspension parameter which we assume to be roughly $10^{-3}$ based on the results of Smith and McLean (1977), and $S$ is the normalized excess shear stress, $S=\left(\tau_{s f}-\tau_{c r}\right) / \tau_{c r}$, where $\tau_{s f}$ is the shear stress at the surface of the bed and $\tau_{c r}$ is the critical shear stress required for the initiation of sediment motion. We obtain $z_{a}$ based on a rough estimate for the particle saltation height, 2D, where $D$ is the grain size (Wiberg et al., 1994). In addition, for simplicity we have assumed $f_{\mathrm{i}}$ as 1 . This assumption is less true for bed material within the lagoon where the 
coarser grains in suspension compose a much smaller fraction of the original muddy/silt substrate. Our calculations for $q_{s}$ in the lagoon during inundation should therefore be considered an upper bound. This estimate is still useful since we are assessing whether the maximum equilibrium suspended sediment flux in the lagoon is significantly smaller than the flux advected in from the barrier. Finally, we assume a smooth bed such that, $\tau_{s f}=\tau_{o}=\rho C_{D} U^{2}$, where $\tau_{o}$ is the effective bed shear stress experienced by the flow. Methods for obtaining $U$ and the drag coefficient, $C_{D}$ in the lagoon are described in Appendix DR4. A drag coefficient of 0.003 is assumed over the barrier during flooding which is consistent with mean $C_{D}$ values observed in the surf zone by Feddersen et al. (2003). To estimate $\tau_{c r}$ a constant dimensionless critical shear stress, $\tau *_{c r}$ of 0.06 is assumed which is reasonable for the flow conditions and grain sizes considered (Wiberg and Smith, 1987), where

$$
\tau_{*_{c r}}=\frac{\tau_{c r}}{\operatorname{Dg}\left(\rho_{s}-\rho\right)}
$$

In this expression $\tau_{c r}$ is the critical shear stress at the bed for the initiation of motion of a particle with a diameter of $D$ and a density $\rho_{s}$, in a fluid with a density of $\rho$, and $g$ is the acceleration of gravity.

Finally, for this analysis velocity is expressed with a logarithmic velocity distribution,

$$
U(z)=\frac{u_{*}}{\kappa} \ln \left(\frac{z}{z_{o}}\right)
$$

Where $z_{o}$ is the bed roughness length (Appendix DR4).

Introducing the suspension distribution, Eq. 5.2 and the expression for velocity, Eq. 5.5 into Eq. 5.1 we obtain, 


$$
q_{s}=\int_{z_{a}}^{h} \frac{u_{*}}{\kappa} \ln \left(\frac{z}{z_{o}}\right) C_{a}\left(\frac{z}{z_{a}}\right)^{-R o} d z
$$

which integrates to,

$$
q_{s}=\frac{u_{*} C_{a}}{\kappa(R o-1)^{2}}\left(z_{a}\left((R o-1) \ln \left(\frac{z_{a}}{z_{o}}\right)+1\right)-h\left(\frac{h}{z_{a}}\right)^{-R o}\left((R o-1) \ln \left(\frac{h}{z_{o}}\right)+1\right)\right)
$$

Table DR3 presents the results of using Eq. 5.7 with the inundation conditions estimated at the site, and for the $\mathrm{D}_{95}$ grains observed in Core 3 (Table DR2 and Figure 4 in main text). Estimated bottom shear stresses, $\tau_{o}$, drop significantly from 59-118 Pa along the barrier to 6-21 $\mathrm{Pa}$ within the lagoon. Consequently, the Rouse suspension parameter, $R_{o}$ increase from $0.5-0.8$ over the barrier to $1.5-2.0$ within the lagoon. In both cases $R_{o}$ transitions from $>1$ over the barrier to $<1$ within the lagoon. This suggests that near bed vertical velocity fluctuations dominate over particle settling rates for flows over the barrier, but transition in the lagoon to a regime where particle settling can overcome turbulent mixing. Excess shear stresses (S) also decrease by a factor of 10 in the lagoon (Table DR3). The net result is suspended sediment fluxes from the barrier being approximately 100-1000 times greater than resuspension fluxes within the lagoon, strongly suggesting that the settling of sediment advected in from the barrier dominates over lagoon resuspension. 
TABLE DR3. ESTIMATES FOR EQUILIBRIUM SUSPENDED SEDIMENT FLUX

\begin{tabular}{lcccccccc} 
Location & $\begin{array}{c}h \\
(\mathrm{~m})\end{array}$ & $\begin{array}{c}U \\
(\mathrm{~m} / \mathrm{s})\end{array}$ & $C_{D}$ & $\begin{array}{c}D \\
(\mathrm{~mm})\end{array}$ & $\begin{array}{c}\tau_{o} \\
(\mathrm{~Pa})\end{array}$ & $S$ & $R o$ & $\begin{array}{c}q_{s} \\
\left(\mathrm{~m}^{2} / \mathrm{s}\right)\end{array}$ \\
\hline \multicolumn{7}{l}{ Flooding depth over barrier $=2 \mathrm{~m}$} \\
Barrier & 2.0 & 4.4 & 0.003 & 0.4 & 59 & 151 & 0.5 & $2 \times 10^{-2}$ \\
Lagoon & 3.5 & 2.5 & 0.001 & 0.4 & 6 & 15 & 1.5 & $9 \times 10^{-6}$
\end{tabular}

Flooding depth over barrier $=4 \mathrm{~m}$

\begin{tabular}{lrrrrrrrr} 
Barrier & 4.0 & 6.3 & 0.003 & 1.0 & 118 & 120 & 0.8 & $9 \times 10^{-3}$ \\
Lagoon & 5.4 & 4.6 & 0.001 & 1.0 & 21 & 21 & 2.0 & $3 \times 10^{-5}$ \\
\hline
\end{tabular}

\section{Appendix DR6: Discussion of deposit genesis: hurricanes versus tsunamis}

We have interpreted that a majority of the deposits in the LPG record are the result of intense hurricane events. This is primarily due to the high frequency of hurricane strikes to the site, and the correlation of historical hurricanes to overwash deposits. Tsunami occurrences at the site are much less frequent with 1 documented event greater than 2 m over the last 500 years (O'Loughlin and Lander, 2003). During hurricane activity the beach at LPG is highly dissipative (Appendix DR3). Studies suggest that under these conditions infragravity waves ( $\mathrm{T}=0.3$ to 4 minutes) account for between roughly $63 \%$ to $98 \%$ of the swash height (Ruessink et al., 1998). These low frequency infragravity oscillations are still shorter than a typical tsunami event whose period can range between 10 minutes and 2 hours (Mei, 1989). We see no evidence in the LPG record for an anomalous deposit that might represent a significant tsunami event. However, hurricane flooding at LPG may still mimic smaller scale tsunami events whose periods and wave heights are closer in magnitude to those occurring during a storm (Morton et al., 2007). We are therefore currently unable to unequivocally assess the 
origin for any individual deposit prior to the documented record, however, the high frequency of both hurricane occurrences and overwash layers observed at LPG, along with the correlation of recent overwash layers to documented intense hurricanes strikes, strongly suggests that a majority of the overwash layers observed at LPG are the result of intense hurricane activity rather than tsunami events.

\section{References:}

Croudace, I.W., Rindby, A., and Rothwell, R.G., 2006, ITRAX: description and evaluation of a new multi-function X-ray core scanner: London, Geological Society.

Donnelly, J.P., and Woodruff, J.D., 2007, Intense hurricane activity over the past 5,000 years controlled by El Nino and the West African monsoon: Nature, v. 447, p. 465-468.

Feddersen, F., Gallagher, E.L., Guza, R.T., and Elgar, S., 2003, The drag coefficient, bottom roughness, and wave-breaking in the nearshore: Coastal Engineering, v. 48, p. 189-195.

Ferguson, R.I., and Church, M., 2004, A simple universal equation for grain settling velocity: Journal of Sedimentary Research, v. 74, p. 933-937.

Fredsoe, J., and Deigaard, R., 1992, Mechanics of coastal sediment transport: Singapore, World Scientific, $369 \mathrm{p}$.

Graf, W.H., 1971, Hydraulics of Sediment Transport: Littleton, CO, USA, Water Resour. Publ.

Hsu, S.A., Martin, M.F., Jr., and Blanchard, B.W., 2000, An Evaluation of the USACE's Deepwater Wave Prediction Techniques under Hurricane Conditions During Georges in 1998: Journal of Coastal Research, v. 16, p. 823-829.

Hughen, K.A., Baillie, M.G.L., Bard, E., Beck, J.W., Bertrand, C.J.H., Blackwell, P.G., Buck, C.E., Burr, G.S., Cutler, K.B., Damon, P.E., Edwards, R.L., Fairbanks, R.G., Friedrich, M., Guilderson, T.P., Kromer, B., McCormac, G., Manning, S., Ramsey, C.B., Reimer, P.J., Reimer, R.W., Remmele, S., Southon, J.R., Stuiver, M., Talamo, S., Taylor, F.W., van der Plicht, J., and Weyhenmeyer, C.E., 2004, Marine04 marine radiocarbon age calibration, 0-26 cal kyr BP: Radiocarbon, v. 46, p. 1059-1086.

Landsea, C.W., Anderson, C., Charles, N., Clark, G., Dunion, J., Fernandes-Partagas, J., Hungford, P., Neumann, C.J., and Zimmer, M., 2004, The Atlantic Hurricane Database Re-analysis Project Documentation for 1851-1910 Alterations and Addition to the HURDAT Database, in Murnane, R., and Liu, K.B., eds., Hurricanes and Typhoons: Past, Present and Future: New York City, Columbia University Press, p. 178-221.

McLean, S.R., 1992, On the calculation of suspended load for noncohesive sediments: Journal of Geophysical Research, v. 97, p. 5759-5770. 
Mei, C.C., 1989, The Applied Dynamics of Ocean Surface Waves, in Liu, P.L.-F., ed., Advances Series on Ocean Engineering, Volume 1: Singapore, World Scientific, p. 740.

Morton, R.A., Gelfenbaum, G., and Jaffe, B., 2007, Physical criteria for distinguishing sandy tsunami and storm deposits using modern examples: Sedimentary Geology, v. 200, p. 184-207.

O'Loughlin, K.F., and Lander, J.F., 2003, Caribbean Tsunamis: A 500-year history from 1498-1998: The Netherlands, Kluwer Academic Publishers.

Ochi, M.K., 1998, Ocean Waves: Cambridge, U.K., Cambridge University Press.

Reimer, P.J., Baillie, M.G.L., Bard, E., Bayliss, A., Beck, J.W., Bertrand, C.J.H., Blackwell, P.G., Buck, C.E., Burr, G.S., Cutler, K.B., Damon, P.E., Edwards, R.L., Fairbanks, R.G., Friedrich, M., Guilderson, T.P., Hogg, A.G., Hughen, K.A., Kromer, B., McCormac, G., Manning, S., Ramsey, C.B., Reimer, R.W., Remmele, S., Southon, J.R., Stuiver, M., Talamo, S., Taylor, F.W., van der Plicht, J., and Weyhenmeyer, C.E., 2004, IntCal04 terrestrial radiocarbon age calibration, 0-26 cal kyr BP: Radiocarbon, v. 46, p. 1029-1058.

Ruessink, B.G., Kleinhans, M.G., and van den Beukel, P.G.L., 1998, Observations of swash under highly dissipative conditions: Journal of Geophysical Research, v. 103, p. 3111-3118.

Smith, J.D., and McLean, S.R., 1977, Spatially averaged flow over a wavy surface: Journal of Geophysical Research, v. 82, p. 1735-1746.

Soulsby, R., 1997, Dynamics of marine sands: London, Thomas Telford Publications, $249 \mathrm{p}$.

Stockdon, H.F., Holman, R.A., Howd, P.A., and Sallenger, A.H., Jr., 2006, Empirical parameterization of setup, swash, and runup: Coastal Engineering, v. 53, p. 573588.

Syvitski, J.P.M., Asprey, K.W., and Clattenburg, D.A., 1991, Principles, design, and calibration of settling tubes, in Syvitski, J.P.M., ed., Principles, methods, and application of particle size analysis: Cambridge, Cambridge University Press, p. 45-63.

Wang, D.W., Mitchell, D.A., Teague, W.J., Jarosz, E., and Hulbert, M.S., 2005, Extreme Waves Under Hurricane Ivan: Science, v. 309, p. 896.

Whitham, G.B., 1974, Linear and nonlinear waves: New York, Wiley.

Wiberg, P.L., Drake, D.E., and Cachione, D.A., 1994, Sediment resuspension and bed armoring during high bottom stress events on the northern California inner continental shelf: measurements and predictions: Continental Shelf Research, v. 14, p. 1191-1219.

Wiberg, P.L., and Smith, D.E., 1987, Calculations of the Critical Shear Stress for Motion of Uniform and Heterogeneous Sediments: Water Resource Research, v. 23, p. 1471-1480. 